никами образовательного процесса. Использование данного метода дает возможность организации групповой работы студентов. Чаще такая работа проводится в парах или малых группах при осмотре лор-органов вместе с преподавателем. В клиническом разборе больного преподаватель направляет деятельность студентов, осуществляет анализ полученных результатов осмотра больного, данных обследования пациента, обсуждение основного диагноза. Итогом такой работы является написание истории болезни курируемого больного. Преподаватели используют различные интерактивные способы на практических занятиях: решение ситуационных задач, выполнение тестовых заданий, проведение ролевых игр, в которых студенты выступают в ролях пациентов и врачей-оториноларингологов. Студентам предлагается сцена общения «врач - больной». При этом «пациенту» необходимо высказать жалобы, представить анамнез жизни и анамнез болезни по заданной патологии. «Врач» осматривает «пациента», описывает должные объективные данные, выставляет предполагаемый диагноз.

Следующая группа студентов на основании полученных предыдущей группой клинических данных, данных дополнительных методов исследования составляет алгоритм диагностики заболевания и проводит дифференциальную диагностику с заболеваниями, имеющими похожую симптоматику.

Третья группа студентов выставляет окончательный диагноз и приводит его обоснование.

Роль преподавателя заключается в содействии студентам в данном процессе. Преподаватель ненавязчиво корректирует ответы обучающихся, направляет их в нужное русло, предоставляет дополнительную информацию, акцентирует внимание на упущенных деталях. Усилия и внимание педагога должны быть направлены на построение эффективного взаимодействия обучающихся. Эту цель организации взаимодействия (интеракции) студентов в учебной группе необходимо учитывать при планировании занятий.

Одним из методов модерации является визуализация, дающая возможность определять результаты и достижения обучающихся. Активные методы представления информации, различные техники и способы визуализации материала оживляют образовательный процесс и положительно сказываются на результатах обучения. Красочно оформленные презентации по изучаемой теме, лекции-презентации, учебные пособия, работа в операционной, перевязочной и смотровом кабинете с преподавателем создают позитивный настрой у студентов к приобретению знаний по оториноларингологии. Используя визуализированные методы в образовательном процессе, преподавателям легче оценивать результаты занятий, а обучающимся вспоминать и закреплять новый материал. Кроме того, подключение зрительной памяти обеспечивает повышенную выживаемость знаний, позволяет активно использовать новые знания в сочетании с уже имеющимися. Таким образом, уход от традиционной формы обучения и переход к использованию активных методов обучения позволяет повысить образовательный уровень, более эффективно использовать время теоретической и практической подготовки, формировать у студентов способность работать в команде для достижения основной цели.

\title{
УДК: 378
}

\section{В.В. Бобрович, О.В. Ходакова}

\author{
ФГБОУ ВО Читинская ГМА Минздрава России, Чита, Россия
}

\section{ОРГАНИЗАЦИЯ ПРИЕМНОЙ КАМПАНИИ КАК ИНСТРУМЕНТ УПРАВЛЕНИЯ КАЧЕСТВОМ ПОДГОТОВКИ СПЕЦИАЛИСТОВ}

Резюме Качество образования в высшей школе необходимо рассматривать не только с позиции оценки его процесса и результатов, но и с позиции обеспечения качества ресурсов. Контингент абитуриентов во многом определяет то, какие стартовые позиции будет иметь вуз при осуществлении подготовки специалистов. От эффективной организации приемной кампании будет зависеть качественный состав обучающихся, а, следовательно, и результаты образовательного процесса. алистов.

Ключевые слова: высшее медицинское образование, приемная кампания, подготовка специ-

\section{ORGANIZATION OF THE ADMISSION CAMPAIGN AS A WAY OF QUALITY MANAGEMENT OF THE TRAINING OF SPECIALISTS}

\author{
V.V. Bobrovich, O.V. Khodakova
}

FSBEI HE Amur SMA HM, Blagoveshchensk, Russia

\begin{abstract}
The quality of education in the Higher School should be considered not only from the point of view of its process and results evaluation, but also from the viewpoint of ensuring the quality of resources. The contingent of applicants largely determines which starting positions the institution will have when training specialists. The qualitative contingent of the students, and, consequently, the results of the educational process will depend on the effective organization of the admission campaing.
\end{abstract}

Key words: higher medical education, admission campaign, training of specialists.

В настоящее время, высшие учебные заведения стали полноправными субъектами рыночной экономики, получив право самостоятельно определять направления своего развития, цели и методы их достижения. Этому способствовало, в том числе, принятие Федерального Закона от 29.12.2012 № 273-Ф3 «Об образовании в Российской Федерации». Повысились требования 
общества к качеству образования, кардинально обновлены технологии обучения, быстро меняются организационные и экономические условия деятельности вузов, обостряется конкурентная борьба на рынке образовательных услуг, постоянно меняется позиция государства по отношению к высшей школе. Рост самостоятельности и свободы вузов привел к росту ответственности вузов за эффективность своей деятельности. Направленность вузов на выживание требует изменений в процессах управления. Решение задач адаптации, выживания и развития в новых условиях обязывают вузы не только отслеживать состояние рынка образовательных услуг и оценивать свое положение на этом рынке, но и применять методы прогнозирования развития рынка, разрабатывать альтернативные варианты своего будущего поведения в зависимости от изменения внешней среды [2].

С практической точки зрения большой интерес представляет качество высшего образования (подготовки специалистов). Согласно стандартам ИСО (ISO) серии 9000, под качеством следует понимать степень соответствия свойств какого-то объекта (продукта, услуги, процесса) определенным требованиям (нормам, стандартам) [1]. Таким образом, качество высшего образования (ВО) - это сбалансированное соответствие всех аспектов высшего образования определенным целям, потребностям, требованиям, нормам и стандартам. При этом следует учитывать, что К определению качества ВО необходим многосторонний подход.

Во-первых, перед высшим образованием ставятся определенные цели, как внешние, так и внутренние. Оно должно соответствовать установленным образовательным стандартам и нормам. Для получения действительно качественного образования должно быть обеспечено качество самих требований (целей, стандартов и норм) и необходимые качественные ресурсы (образовательные программы, кадровый потенциал, контингент абитуриентов, материально-техническое обеспечение, финансы и т.д.), т.е. качество условий (вложений в образование). При соблюдении этих аспектов качества важную роль играет качество образовательных процессов (научная и учебная деятельность, управление, образовательные технологии и т.д.), непосредственно реализующих (обеспечивающих) подготовку специалистов. И, наконец, еще одним элементом качества образования является качество результатов деятельности вуза (текущие и итоговые результаты обучения студентов, характеристики трудоустройства, карьерного роста выпускников и т.д.) [2].

Если рассматривать такие качественные ресурсы, как образовательные программы, кадровый потенциал, материально-техническое обеспечение, финансы, необходимо отметить, что в основном они зависят от позиции руководства вуза, стратегии развития образовательной организации. В то время как контингент абитуриентов зависит от многих невзаимосвязанных факторов: состояния территориальных образовательных систем; положения региона на географической карте России, его экономическое развитие и привлекательность для осуществления профессиональной деятельности; развития внешней транспортной инфраструктуры региона и др.

Контингент абитуриентов во многом определяет то, какие стартовые позиции будет иметь вуз при осуществлении подготовки специалистов. Важнейшую роль в координации взаимодействия между выпускниками общеобразовательных организаций и вузом играет приемная кампания вуза. Именно от правильной и слаженной организации приема зависит качественный состав обучающихся, а, следовательно, и результаты образовательного процесса.

Эффективность проведения приемной кампании зависит от ряда субъективных и объективных параметров. Субъективные параметры - это непосредственно то, как организована приемная кампания, то, на что она может повлиять, как на подготовительном этапе, так и в ходе приема. Основными инструментами здесь может выступать организация профориентационной работы, центров довузовской подготовки, создание научных и экспериментальных площадок, участие в проведении олимпиад, включенных в перечень олимпиад школьников. Но, к сожалению, есть и объективные параметры, которые могут повлиять на результат приема, и основным из них является базовый уровень подготовки абитуриентов.

Сложившийся инструментарий оценки качества подготовки выпускников системы общего образования через процедуру ЕГЭ позволяет проводить оценку, используя единую шкалу оценивания. Таким образом, независимость оценочных процедур, как основополагающий принцип организации контроля качества образования, позволяет выявить наиболее подготовленных выпускников и вносит некоторую ясность о контингенте абитуриентов при проведении приемной кампании.

Однако, при этом необходимо отметить, что согласно Порядку приема (приказ МОН РФ от 14.10.2015 г. № 1147 (с изм. и доп.), при поступлении в вуз абитуриент может подать документы в пять образовательных организаций, в каждой из которых участвовать в конкурсе по трем специальностям и (или) направлениям подготовки. Сложившаяся система оценочных процедур создает предпосылки для миграции наиболее подготовленных абитуриентов в более привлекательные, по их мнению, вузы и регионы. В таком случае в наименее выгодном положении при проведении приемной кампании оказываются вузы, находящиеся в отдаленных от центральной части России регионах.

Анализ контингента поступавших в Читинскую государственную медицинскую академию за период 2014-2017 гг. позволил выявить некоторые особенности, связанные с уровнем их подготовки по основным общеобразовательным предметам, необходимым для поступления. Основой для анализа послужили данные о результатах ЕГэ школьников по предметам «Химия» и «Биология», а также материалы приемной кампании академии за анализируемый период.

На протяжении четырехлетнего периода можно отметить снижение среднего балла ЕГэ по обоим предметам. Наиболее существенное снижение можно отметить по предмету «Биология» - с 50,01 до 44,47 баллов (на 11\%), при этом основное падение показателя 
отмечается в 2017 году. В течение всего периода растет доля неудовлетворительных результатов по обоим предметам - с 15 до 25\% по химии и с 9 до 29\% по биологии. Количество сдающих ЕГЭ практически не меняется (как в абсолютных значениях, так и в показателях).

В ходе анализа оценивался средний балл ЕГЭ по указанным предметам не только по региону, но и по каждому муниципальному образованию. Необходимо отметить, что из 33 муниципальных образований средний балл ЕГЭ по химии оказался ниже установленного минимального порогового значения (36 баллов) в 7 муниципальных образованиях (22\%), по биологии - в 8 муниципальных образованиях (25\%). Средний балл ЕГЭ в этих районах (образованиях) составил от 21 до 35 баллов. В двух муниципальных образованиях ЕГЭ по химии и биологии не проводись вообще (2017 год). Подобная ситуация отмечалась и в предыдущие годы, при этом в некоторых муниципальных образованиях нет попыток сдачи ЕГЭ по химии и биологии в течение трех лет подряд.

Особый интерес представляют данные о количестве лиц, сдавших ЕГэ (по химии и биологии) и подавших заявления на поступление. На протяжении четырех лет от 6 до 20\% выпускников, сдавших ЕГЭ по профильным для медицинского вуза предметам, не подают заявления на поступление в вуз, расположенный на территории региона. Как правило, это абитуриенты, имеющие наиболее высокие результаты. К сожалению, отток из региона наиболее подготовленных абитуриентов приводит к тому, что средний проходной балл на места в рамках контрольных цифр приема за счет бюджетного финансирования (КЦП) оказывается существенно ниже общероссийских показателей.

В образовательных организациях высшего образования, подведомственных Минздраву России, более $50 \%$ мест в рамках КЦП выделяется для подготовки специалистов в рамках целевого приема. Особенности правового регулирования целевого приема таковы, что заказчик самостоятельно определяет контингент направляемых на обучение абитуриентов. Несмотря на значение показателя в целевой конкурсной группе равного 1,3 человека на место, фактически сложившиеся проходные баллы по каждому направлению подготовки существенно ниже проходных баллов в общеи конкурсной группе. Таким образом, более половины поступивших на места в рамках КЦП, имеют средние проходные баллы значительно ниже общероссийских показателей. В период обучения указанный контингент имеет низкие показатели успеваемости (промежуточной аттестации). Доля отчисленных «целевиков» по разным направлениям подготовки составляет от 12 до $45 \%$.

Перечисленные особенности контингента абитуриентов создают определенные риски, связанные с возможностью неполучения максимальных результатов в ходе процесса обучения. Администрации вуза необходимо организовывать образовательный процесс, учитывая низкий базовый уровень подготовки поступающих как по профильным предметам, так и, как правило, по всему блоку дисциплин гуманитарного профиля.

Инструментом нивелирования указанных рисков может выступать эффективная организация приемной кампании. Необходима системная работа, которая должна состоять не только из профориентационной деятельности и осуществлении предметной подготовки поступающих на довузовском этапе, но и из взаимодействия вуза с представителями территориальной системы основного общего образования, участия в программах повышения квалификации педагогических кадров системы общего образования, координации совместной работы с заказчиком в рамках целевого приема и обучения, создания системы дополнительных социальных гарантий для абитуриентов, имеющих высокие результаты ЕГЭ, привлечения абитуриентов из других регионов.

Резюмируя вышесказанное и подводя итоги, можно сделать следующие выводы.

1. Рассматривать вопросы качества образования в высшей школе необходимо не только с позиции оценки его процесса и результатов, но и с позиции обеспечения качества ресурсов.

2. Организация приемной кампании является важным инструментом управления качеством образования в

3. Для эффективной организации приемной кампании необходима программа нивелирования как субъективных, так и объективных рисков.

\section{Литература}

1. ГОСТ ISO 9000 - 2011. Межгосударственный стандарт. Системы менеджмента качества. Основные положения и словарь (ISO 9000:2005, IDT) Quality management systems. Fundamentals and vocabulary (введен в действие с 1 января 2013 года Приказом Росстандарта от $22.12 .2011 \mathrm{~N} 1575-\mathrm{ct}$ ).

2. Ганжа О.А., Кулик О.Г., Рогозин Н.А., Чмак О.В. Управление качеством в высшем образовании: монография / [О.А. Ганжа, О.Г. Кулик, Н.А. Рогозин, О.В. Чмак]; М-во образования и науки Российской Федерации; Волгогр. гос. архит.-строит. ун-т; Волж. ин-т стр-ва и технологий(филиал) ВолгГАСУ. Волгоград: ВолгГАСУ, 2014.152 [1]с.

3. Зеленова Л.П., Кац А.М. Система управления качеством образования и оценка качества образовательных услуг образовательных организаций // [Электронный ресурc] URL: http://www.apkpro.ru/doc 